\section{BAN DRUG ADVERTISEMENTS}

To the editor: In 2009, I published an opinion piece in the Canadian Journal of Emergency Medicine (CFEM) calling for the journal to stop accepting advertisements from pharmaceutical companies. ${ }^{1}$ The president of the Canadian Association of Emergency Physicians (CAEP) replied that "CAEP's current position is that relationships between CAEP and industry, including pharmaceutical companies, are acceptable." 2 Now comes news that Emergency Medicine Australasia, the journal of the Australasian College for Emergency Medicine, is going to ban advertisements. In a joint statement, two of the editors said, "It is time to show leadership and make a stand, and medical journals have a critical role to play in this... We invite other journals to show their support and follow suit by declaring their hand and doing the same." ${ }^{3}$ CAEP and CFEM should follow the leadership from Australia.

Competing interests: In 2007, I was a consultant to a law firm representing Apotex Inc regarding the influence of promotion on sales. In 2007-2008, I was a consultant to the Canadian federal government in its defense against a lawsuit challenging the ban on direct-to-consumer advertising. In 2010, I was a consultant to a law firm regarding a lawsuit against Allergan Inc.

\section{Joel Lexchin, MD}

Professor, School of Health Policy and Management, York University, Toronto, $\mathrm{ON}$

\section{References}

1. Lexchin J. CJEM and pharmaceutical advertisements: it's time for an end. CFEM 2009;11:375-9.

2. Evan C. CJEM and pharmaceutical advertisements. CFEM 2010;12:5.

3. Rose D. Medical journal bans drug company ads. Sydney Morning Herald, February 3, 2011. Available at: http:// news.smh.com.au/breaking-news-national/ medical-journal-bans-drug-company-ads20110203-1aev8.html (accessed February $3,2011)$. 